\title{
Intracranial Stenting; the Current Landscape
}

\author{
Dong Joon Kim, MD, PhD \\ Department of Radiology, Severance Hospital, Yonsei University College of Medicine, Seoul, Korea
}

Intracranial atherosclerotic stenosis (ICAS) is one of the most common causes of stroke worldwide, and it is of special concern in the Asian population due to its higher prevalence. ${ }^{1,2}$ ICAS is the cause of ischemic stroke in 30-50\% in Asians, compared to $8-10 \%$ in North America. ${ }^{2}$ The high recurrence rate and the disability caused by the stroke warrants a safe and effective treatment method. Bypass surgery as well as endovascular treatment have been tested against best the medical therapy, but current best evidence does not support either surgery or intervention as the primary treatment modality for ICAS lesions (Table 1). ${ }^{3-6}$

In this regard, the Stenting and Aggressive Medical Management for Preventing Recurrent Stroke in Intracranial Stenosis (SAMMPRIS) randomized trial and its post-hoc studies in addition to the single-arm Wingspan Stent System Post Market Surveillance (WEAVE) trial and its 1 year follow up results (Wingspan One-year Vascular Events and Neurologic Outcomes [WOVEN] trial) published last year shed some insights into the importance of patient selection concerning who may or may not benefit from intracranial stenting for ICAS lesions. ${ }^{4,7,8}$

The WEAVE trial adhered strictly to the US Food and Drug Administration (FDA) on label usage criteria in terms of patient age, stenosis degree, baseline neurological status, type of stroke, medical failure, and time to intervention, resulting in a highly selected group of patients for stenting (Table 1). ${ }^{7}$ The results of the 1-year follow-up of the WEAVE trial (WOVEN trial) showed a primary endpoint rate of $8.5 \%$. Postperiprocedural (1 month to 1 year) event rates were comparable between the WOVEN (5.4\%) vs. SAMMPRIS stenting (5.3\%) vs. SAMMPRIS aggressive medical management (AMM, 6.5\%) results. Moreover, most of the strokes in the postperiprocedural period were minor strokes (6 of 7 cases) suggesting that decreasing the periprocedural event rate is critical and that there may be clinical benefits of stenting at 1 year follow up in these selected patients. ${ }^{7,8}$ This is uplifting news; however, good single-arm interventional results have not been duplicated in double-arm studies for ICAS. Further trials comparing these best stenting protocols with the best medical therapy are warranted.

Another important insight is that the pathological mechanism of stroke should be distinguished. There is growing evidence that patients with hemodynamic dominant stroke may benefit most in contrast to those with perforator stroke. Although most subgroup analyses of the SAMMPRIS study did not show favorable results for the stenting

\section{Correspondence to:} Dong Joon Kim, MD, PhD

Department of Radiology, Severance Hospital, Yonsei University College of Medicine, 50-1 Yonsei-ro, Seodaemun-gu, Seoul 03722, Korea

Tel: +82-2-2228-7400

Fax: +82-2-393-3035

E-mail : djkimmd@yuhs.ac

Received: February 16, 2021

Revised: February 19, 2021

Accepted: February 19, 2021
Copyright $\odot 2021$ Korean Society of Interventional Neuroradiology

This is an Open Access article distributed under the terms of the Creative Commons Attribution Non-Commercial License (http://creativecommons.org/licenses/by-nc/4.0) which permits unrestricted non-commercial use, distribution, and reproduction in any medium, provided the original work is properly cited.

pISSN 2093-9043 eISSN 2233-6273 
Table 1. Summary of intracranial stenosis trials

\begin{tabular}{|c|c|c|c|c|c|c|}
\hline Trial & Study design & Indication & Interval & $\begin{array}{l}\text { Primary } \\
\text { endpoint }\end{array}$ & $\begin{array}{l}\text { Periprocedural risk/ } \\
\text { safety outcome }\end{array}$ & $\begin{array}{l}\text { Long term } \\
\text { FU }\end{array}$ \\
\hline EC-IC bypass ${ }^{3}$ & $\begin{array}{l}\text { Randomized, } \\
\text { multicenter } \\
\text { Best medical care } \\
\text { (ASA)+STA/MCA } \\
\text { bypass vs. best } \\
\text { medical care }\end{array}$ & $\begin{array}{l}\text { Recent hemispheric stroke, } \\
\text { retinal infarction, TIA with } \\
\text { atherosclerotic narrowing } \\
\text { or occlusion of ipsilateral } \\
\text { ICA or MCA }\end{array}$ & $\begin{array}{l}\text { Randomization } \\
\text { to surgery; } \\
9 \text { days }\end{array}$ & $\begin{array}{l}14 \% \\
\text { increase } \\
\text { of relative } \\
\text { risk in } \\
\text { surgical } \\
\text { group }^{*}\end{array}$ & $0.6 \% \& 2.5 \%^{\dagger}$ & \\
\hline WASID 5 & $\begin{array}{l}\text { Randomized, } \\
\text { multicenter } \\
\text { Warfarin vs. ASA }\end{array}$ & $\begin{array}{l}\text { TIA or stroke caused by } \\
\text { 50-99\% symptomatic } \\
\text { major intracranial stenosis }\end{array}$ & & $\begin{array}{l}21.8 \% \text { vs. } \\
22.1 \% \\
(p=0.83, \\
\text { at } 1.8 \text { year } \\
\quad F U)^{\ddagger}\end{array}$ & $\begin{array}{l}\text { Death } 9.7 \% \text { vs. } 4.3 \% \text { / } \\
\text { Major hemorrhage } \\
8.3 \% \text { vs. } 3.2 \% \text {, ( } p=0.02 / \\
p=0.01 \text {, at } 1.8 \text { year } \\
\text { FU) }\end{array}$ & \\
\hline SAMMPRIS $^{4,15}$ & $\begin{array}{l}\text { Randomized, } \\
\text { multicenter } \\
\text { Wingspan } \\
\text { stent+AMM vs. } \\
\text { AMM (ASA for entire } \\
\text { FU+clopidogrel } \\
\text { for } 90 \text { days+BP/ } \\
\text { LDL cholesterol } \\
\text { control+lifestyle } \\
\text { modification } \\
\text { program) }\end{array}$ & $\begin{array}{l}\text { Recent TIA or stroke } \\
\text { attributed to 70-99\% } \\
\text { stenosis of major } \\
\text { intracranial artery }\end{array}$ & $\begin{array}{l}\text { Symptom to } \\
\text { randomization; } \\
7 \text { days vs. } \\
7 \text { days (median) }\end{array}$ & $\begin{array}{c}20.0 \% \text { vs. } \\
12.2 \% \\
(p=0.009 \\
\text { at } 1 \text { year })^{\S}\end{array}$ & $\begin{array}{l}30 \text { day stroke/death; } \\
14.7 \% \text { vs. } 5.8 \% \\
(p=0.002)\end{array}$ & $\begin{array}{l}23 \% \text { vs. } 15 \% \\
(p=0.0252, \\
\text { at median } \\
32.4 \text { month } \\
\quad F U)^{++}\end{array}$ \\
\hline VISSIT ${ }^{6}$ & $\begin{array}{l}\text { Randomized, } \\
\text { multicenter } \\
\text { Balloon expandable } \\
\text { stent+medical vs. } \\
\text { medical }\end{array}$ & $\begin{array}{l}\text { Symptomatic ICAS (70-99\%) } \\
\text { involving ICA, MCA, VA, BA } \\
\text { with a hard TIA or stroke } \\
\text { attributable to the target } \\
\text { lesion within the past } 30 \\
\text { days }\end{array}$ & $\begin{array}{l}\text { Event to } \\
\text { randomization; } \\
12.3 \text { vs. } \\
15.2 \text { days } \\
\text { (mean) }\end{array}$ & $\begin{array}{c}36.2 \% \text { vs. } \\
15.1 \% \\
(p=0.02 \\
\text { at } 1 \text { year) }\end{array}$ & $\begin{array}{l}\text { Any stroke, death, or } \\
\text { ICH within } 30 \text { days of } \\
\text { randomization+any } \\
\text { hard TIA between } \\
\text { day } 2-30 \text { of } \\
\text { randomization; } 24.1 \% \\
\text { vs. } 9.4 \%(p=0.05)\end{array}$ & \\
\hline WEAVE ${ }^{7}$ & $\begin{array}{l}\text { Single-arm, } \\
\text { multicenter, } \\
\text { Wingspan stent }\end{array}$ & $\begin{array}{l}\text { 22-80 years old, } \\
\text { symptomatic ICAS 70-99\% } \\
\text { (artery } \varnothing \geq 2 \mathrm{~mm} \text { ), baseline } \\
\mathrm{mRS} \leq 3, \geq 2 \text { strokes in the } \\
\text { vascular territory of the } \\
\text { stenotic lesion with at least } \\
1 \text { stroke while on medical } \\
\text { therapy, and stenting } \geq 8 \\
\text { days after the last stroke }\end{array}$ & $\begin{array}{l}\text { Stroke to stent } \\
\text { interval; } 22 \text { days } \\
\text { (median, range; } \\
\text { 8-371 days) }\end{array}$ & $2.6 \%$ & & \\
\hline WOVEN ${ }^{6}$ & WEAVE 1 year FU & & & $8.5 \%^{* *}$ & $\begin{array}{l}\text { Stroke severity; Minor/ } \\
\text { major stroke } n=6 / 1\end{array}$ & \\
\hline
\end{tabular}

EC-IC, Extracranial to intracranial; WASID, Warfarin-Aspirin Symptomatic Intracranial Disease; SAMMPRIS, Stenting and Aggressive Medical Management for Preventing Recurrent Stroke in Intracranial Stenosis; VISSIT, Vitesse Intracranial Stent Study for Ischemic Stroke Therapy; WEAVE, Wingspan Stent System Post Market Surveillance; WOVEN, Wingspan One-year Vascular Events and Neurologic Outcomes; ASA, acetylsalicylic acid; STA, superficial temporal artery; MCA, middle cerebral artery; TIA, transient ischemic attack; ICAS, intracranial atherosclerotic stenosis; ICA, internal carotid artery; VA, vertebral artery; BA, basilar artery; BP, blood pressure; LDL, low density lipoprotein; ICH, intracranial hemorrhage; AMM; aggressive medical management; FU, follow up.

${ }^{*}$ Fatal \& nonfatal stroke. ${ }^{\dagger} 30$ day surgical mortality \& major stroke morbidity rate. ${ }^{\ddagger}$ Ischemic stroke, brain hemorrhage, death from vascular causes other than stroke ${ }^{\S}$ Stroke or death within 30 days after enrollment or after a revascularization procedure for the qualifying lesion during the FU period or ischemic stroke in the territory of the qualifying artery between day 31 and the end of the follow-up period. "Stroke in the same territory within 12 months of randomization or hard TIA in the same territory day 2 through month 12 postrandomization. "Stroke or death within 72 hours. ${ }^{* *}$ Stroke within the target artery territory, non-traumatic hemorrhage, or neurologic death within 1 year following stenting. ${ }^{+1}$ Any stroke or death within 30 days after enrolment, ischaemic stroke in the territory of the qualifying artery beyond 30 days of enrolment, or any stroke or death within 30 days after a revascularisation procedure of the qualifying lesion during follow-up. 
arm, the post-hoc analysis of the medical arm showed that recurrent stroke rates were higher in patients with a borderzone infarct pattern on magnetic resonance imaging/computed tomography and impaired collateral flow (36.7\%) compared to other groups combined $(7.7 \%)(p<0.05)$. The primary endpoint rates were numerically lower in the stenting arm in patients with hemodynamic infarct compared to the AMM arm (18.2\% vs. $26.4 \%)$, suggesting that these patients may be a promising population for stenting. ${ }^{9}$ The WEAVE trial did not systematically exclude patients with perforator-type stroke; however, underdilation of the balloon to $60 \%$ rather than the standard $80 \%$ of the normal vessel diameter was recommended when directly adjacent to visible perforators. The resulting rate of perforator stroke in this trial was only $0.7 \%$.

Issues remain despite these promising new insights. Strict adherence to the conservative FDA indications for ICAS stenting may result in super selection of patients. ${ }^{10}$ Many aspects, including the limitation of patients to medical failure ( $\geq 2$ strokes with at least 1 stroke while on medical therapy), type of qualifying event (stroke or transient ischemic attack), and the time to treatment, may need further investigation. ${ }^{11-14}$ In terms of time to treatment, the current major focus in ICAS stenting is decreasing the high periprocedural risk. Thus, stenting is often delayed to avoid risks associated with unstable plaque and possibly hyperperfusion. ${ }^{15,16} \mathrm{How}$ ever, the recurrent stroke rate is highest in this early post-ictus period; thus, an effective treatment should target this critical period. Lessons learned from recent studies and the ongoing growth of experience in areas, such as rescue intracranial stenting in ICAS related acute stroke, may interplay to open new doors in the near future. ${ }^{17}$

Meanwhile, we await newer insights from the Angioplasty and Stenting for Patients With Symptomatic Intracranial Atherosclerosis (NCT02689037) and the China Angioplasty \& Stenting for Symptomatic Intracranial Severe Stenosis (CASSISS, NCT01763320) trials. ${ }^{18,19}$

\section{Fund}

None.

\section{Conflicts of Interest}

DJK has been the Associate Editor of the Neurointervention since 2018. No potential conflict of interest relevant to this article was reported.

\section{ORCID}

Dong Joon Kim: https://orcid.org/0000-0002-7035-087X

\section{REFERENCES}

1. Wabnitz A, Chimowitz M. Angioplasty, stenting and other potential treatments of atherosclerotic stenosis of the intracranial arteries: past, present and future. J Stroke 2017;19:271-276

2. Wang T, Luo J, Wang X, Yang K, Jadhav V, Gao P, et al. Endovascular therapy versus medical treatment for symptomatic intracranial artery stenosis. Cochrane Database Syst Rev 2020;(8):CD013267.

3. EC/IC Bypass Study Group. Failure of extracranial-intracranial arterial bypass to reduce the risk of ischemic stroke. Results of an international randomized trial. N Engl J Med 1985;313:11911200

4. Chimowitz MI, Lynn MJ, Derdeyn CP, Turan TN, Fiorella D, Lane BF, et al.; SAMMPRIS Trial Investigators. Stenting versus aggressive medical therapy for intracranial arterial stenosis. N Engl J Med 2011;365:993-1003

5. Chimowitz MI, Lynn MJ, Howlett-Smith H, Stern BJ, Hertzberg VS, Frankel MR, et al.; Warfarin-Aspirin Symptomatic Intracranial Disease Trial Investigators. Comparison of warfarin and aspirin for symptomatic intracranial arterial stenosis. N Engl J Med 2005;352:1305-1316

6. Zaidat OO, Fitzsimmons BF, Woodward BK, Wang Z, Killer-Oberpfalzer M, Wakhloo A, et $a_{; ;:}$VISSIT Trial Investigators. Effect of a balloon-expandable intracranial stent vs medical therapy on risk of stroke in patients with symptomatic intracranial stenosis: the VISSIT randomized clinical trial. JAMA 2015;313:1240-1248

7. Alexander MJ, Zauner A, Chaloupka JC, Baxter B, Callison RC, Gupta R, et al.; WEAVE Trial Sites and Interventionalists. WEAVE trial: final results in 152 on-label patients. Stroke 2019;50:889894

8. Alexander MJ, Zauner A, Gupta R, Alshekhlee A, Fraser JF, Toth G, et al. The WOVEN trial: wingspan one-year vascular events and neurologic outcomes. J Neurointerv Surg 2020. doi: 10.1136/ neurintsurg-2020-016208

9. Wabnitz AM, Derdeyn CP, Fiorella DJ, Lynn MJ, Cotsonis GA, Liebeskind DS, et al.; SAMMPRIS Investigators. Hemodynamic markers in the anterior circulation as predictors of recurrent stroke in patients with intracranial stenosis. Stroke 2018. doi: 10.1161/STROKEAHA.118.020840

10. Alexander MJ. Response by Alexander et al to letter regarding article, "WEAVE trial: final results in 152 on-label patients". Stroke 
2019;50:e223

11. Kasner SE, Chimowitz MI, Lynn MJ, Howlett-Smith H, Stern BJ, Hertzberg VS, et al.; Warfarin Aspirin Symptomatic Intracranial Disease Trial Investigators. Predictors of ischemic stroke in the territory of a symptomatic intracranial arterial stenosis. Circulation 2006;113:555-563

12. Turan TN, Maidan L, Cotsonis G, Lynn MJ, Romano JG, Levine SR, et al.; Warfarin-Aspirin Symptomatic Intracranial Disease Investigators. Failure of antithrombotic therapy and risk of stroke in patients with symptomatic intracranial stenosis. Stroke 2009:40:505-509

13. Fiorella D, Derdeyn CP, Lynn MJ, Barnwell SL, Hoh BL, Levy El, et al.; SAMMPRIS Trial Investigators. Detailed analysis of periprocedural strokes in patients undergoing intracranial stenting in stenting and aggressive medical management for preventing recurrent stroke in intracranial stenosis (SAMMPRIS). Stroke 2012;43:2682-2688

14. Lutsep HL, Barnwell SL, Larsen DT, Lynn MJ, Hong M, Turan TN, et al.; SAMMPRIS Investigators. Outcome in patients previously on antithrombotic therapy in the SAMMPRIS trial: subgroup analysis. Stroke 2015;46:775-779
15. Derdeyn CP, Chimowitz MI, Lynn MJ, Fiorella D, Turan TN, Janis LS, et al.; Stenting and Aggressive Medical Management for Preventing Recurrent Stroke in Intracranial Stenosis Trial Investigators. Aggressive medical treatment with or without stenting in high-risk patients with intracranial artery stenosis (SAMMPRIS): the final results of a randomised trial. Lancet 2014;383:333-341

16. Yu W, Jiang WJ. Stenting for intracranial stenosis: potential future for the prevention of disabling or fatal stroke. Stroke Vasc Neurol 2018:3:140-146

17. Baek JH, Kim BM, Heo JH, Kim DJ, Nam HS, Kim YD. Outcomes of endovascular treatment for acute intracranial atherosclerosis-related large vessel occlusion. Stroke 2018;49:2699-2705

18. Cui XP, Lin M, Mu JS, Ye JX, He WQ, Fu ML, et al. Angioplasty and stenting for patients with symptomatic intracranial atherosclerosis: study protocol of a randomised controlled trial. BMJ Open 2016;6:e012175

19. Gao P, Zhao Z, Wang D, Wu J, Cai Y, Li T, et al. China angioplasty and stenting for symptomatic intracranial severe stenosis (CASSISS): a new, prospective, multicenter, randomized controlled trial in China. Interv Neuroradio/ 2015;21:196-204 